\title{
əEffects of Explicit Convection on Future Projections of Mesoscale Circulations, Rainfall, and Rainfall Extremes over Eastern Africa
}

\author{
DECLAN L. FINNEY \\ School of Earth and Environment, University of Leeds, Leeds, United Kingdom \\ JOHN H. MARSHAM \\ School of Earth and Environment, University of Leeds, and National Centre for Atmospheric Science, Leeds, \\ United Kingdom \\ David P. Rowell, Elizabeth J. Kendon, Simon O. Tucker, And Rachel A. Stratton \\ Met Office, Exeter, United Kingdom \\ LAWRENCE S. JACKSON \\ School of Earth and Environment, University of Leeds, Leeds, United Kingdom
}

(Manuscript received 6 May 2019, in final form 13 November 2019)

\begin{abstract}
Eastern Africa's fast-growing population is vulnerable to changing rainfall and extremes. Using the first pan-African climate change simulations that explicitly model the rainfall-generating convection, we investigate both the climate change response of key mesoscale drivers of eastern African rainfall, such as sea and lake breezes, and the spatial heterogeneity of rainfall responses. The explicit model shows widespread increases at the end of the century in mean $(\sim 40 \%)$ and extreme $(\sim 50 \%)$ rain rates, whereas the sign of changes in rainfall frequency has large spatial heterogeneity (from $-50 \%$ to over $+90 \%$ ). In comparison, an equivalent parameterized simulation has greater moisture convergence and total rainfall increase over the eastern Congo and less over eastern Africa. The parameterized model also does not capture 1) the large heterogeneity of changes in rain frequency; 2) the widespread and large increases in extreme rainfall, which result from increased rainfall per humidity change; and 3) the response of rainfall to the changing sea breeze, even though the sea-breeze change is captured. Consequently, previous rainfall projections are likely inadequate for informing many climate-sensitive decisions-for example, for infrastructure in coastal cities. We consider the physics revealed here and its implications to be relevant for many other vulnerable tropical regions, especially those with coastal convection.
\end{abstract}

\section{Introduction}

Robust and well-understood predictions of changes in extreme weather events, particularly rainfall, are urgently needed by impact scientists, engineers, nongovernmental organizations, and governments worldwide to prepare for future climate change (Hoegh-Guldberg et al. 2018). Eastern Africa is no exception, with several

D Denotes content that is immediately available upon publication as open access.

Corresponding author: D. L. Finney, d.l.finney@leeds.ac.uk recent high profile floods and droughts in the region, highlighting vulnerabilities in current climate (Kilavi et al. 2018; Funk et al. 2019).

Many studies of eastern African climate change have already been undertaken (Shongwe et al. 2011; Cook and Vizy 2013; Otieno and Anyah 2013; Rowell et al. 2015; Thiery et al. 2016; Ongoma et al. 2018; Osima et al. 2018; Giannini et al. 2018). Out of these numerous

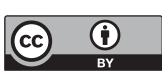

This article is licensed under a Creative Commons Attribution 4.0 license (http://creativecommons.org/ licenses/by/4.0/). 
studies several conclusions paint a picture of how eastern Africa's climate may change:

- Average temperature over eastern Africa could rise by up to $5^{\circ} \mathrm{C}$ by the end of the century under a high emission scenario (Otieno and Anyah 2013; Rowell et al. 2016; Ongoma et al. 2018).

- Temperature rise is shown to be nonuniform across eastern Africa, with additional factors, such as proximity to the ocean, affecting the size of temperature rise (Osima et al. 2018).

- On average, the models show an increase in rainfall, particularly from October to February (Otieno and Anyah 2013; Ongoma et al. 2018).

- The range of rainfall projections is broad, and some models do show a decrease (Rowell et al. 2015).

- Over Lake Victoria, extreme rainfall may increase despite a possible decrease in mean rainfall in response to climate change (Thiery et al. 2016).

While these studies are vital in helping populations prepare, the climate models used so far are limited due to their representation of convection. Several studies have shown that the use of convection-permitting (CP) models-that is, models that represent convection explicitly instead of through approximations (convective parameterizations) can improve the modeled rainfall and its coupling with convergence (Birch et al. 2014; Hohenegger et al. 2015; Finney et al. 2019). A review by Prein et al. (2015) presents results from studies evaluating $\mathrm{CP}$ models against various observations. They show that $\mathrm{CP}$ models can reduce biases in the simulation of the diurnal cycle of precipitation, extreme precipitation, cloud cover, and associated radiation. However, CP models do not necessarily improve the representation of all aspects; for instance, they often to do not greatly reduce biases in mean precipitation (Prein et al. 2015; Jackson et al. 2019). With regard to projections of future climate with CP models, it is notable that they can project greater increases in future extreme rain rates than parameterized climate models (Mahoney et al. 2013; Kendon et al. 2014; Ban et al. 2015; Prein et al. 2017; Kendon et al. 2019). However, until recently CP models have not been applied for continental-scale, tropical climate change simulations.

A new dataset simulating current climate over Africa (Stratton et al. 2018) with a CP model at $4.5-\mathrm{km}$ grid spacing (CP4), and a parameterized convection model at $\sim 25$-km grid spacing (P25), has been shown to improve the representation of both intensity and timing of rainfall associated with deep convection (Finney et al. 2019; Kendon et al. 2019). The same model has also been used to simulate a future climate and has shown that for Africa as a whole, explicit convection increases the change in extreme rainfall (Kendon et al. 2019). For current climate, a decade around the year 2000 is used, with a future-climate simulation applying representative concentration pathway 8.5 (RCP8.5; van Vuuren et al. 2011) changes to greenhouse gases and sea surface temperatures for a decade around year 2100 (giving a $5.2^{\circ} \mathrm{C}$ increase in global mean $1.5-\mathrm{m}$ air temperature).

This new dataset allows us to address critical unanswered questions for eastern Africa, a region already shown to have a different climate change response than much of Africa (Kendon et al. 2019). Here we ask the following questions: Does improved representation of convection support or conflict with projections by parameterized convection, for total, extreme, and frequency of rainfall across the hugely varied climatic zones of eastern Africa? Can a deeper understanding of the drivers of rainfall changes provide confidence in the projections? And specifically, how does the rainfall coupling, or lack of coupling, to atmospheric flows such as the sea breeze affect rainfall projections in the two models?

\section{Data}

Two regional climate models based on the Met Office Unified Model have been independently applied over an African domain (Stratton et al. 2018). Each model has been run for 10 years and 2 months (January 1997February 2007) for current climate, and for 10 years and 2 months for a decade representative of 2100 . All results use the 10 years of simulation following the first 2 months of spinup. In addition to the 2-month spinup, soil moisture has been spun up offline for 10 years using observed meteorological conditions as described further by Stratton et al. (2018). Analysis here uses data archived from the simulations at hourly or 3-hourly frequency, with the exception of the integrated subgrid vertical mass flux, which has been postprocessed as a vertical column integral from monthly mean model level data, and saturation vapor pressure, which has been postprocessed from hourly instantaneous $1.5 \mathrm{~m}$ temperature. The vertical column integral is a density-weighed integral over all model level depths, thereby accounting for varying model depths. All analysis uses complete years of data, without subselecting by season.

\section{a. Setup of global driving model and common regional model}

Both simulations are 1-way nested within an unnudged N512L85 global atmospheric model using the Global Atmosphere/Land 7.0 (GA7/GL7) configuration (Walters et al. 2019). The global model, which includes a convection parameterization, provides lateral boundary conditions to the regional models, and is itself driven by sea surface temperature (SST) analyses (Reynolds et al. 2007). The regional models use this same SST dataset over 
the years 1997-2007. The Unified Model is a nonhydrostatic model based on a semi-implicit, semi-Lagrangian dynamical core. The global and regional configurations involved in this study use "ENDGame" dynamics (Wood et al. 2014). The land surface is simulated using the Joint U.K. Land Environment Simulator (JULES) at the same resolution as the respective regional models and coupled to the atmospheric model. The domain of the regional models encompasses the African continent and is detailed in Stratton et al. (2018), but here we focus on a subset of the data over eastern Africa.

Several lakes within the model domain are represented as inland sea grid cells, many of which are located in eastern Africa (Stratton et al. 2018). Lakes included in the ARCLake, version 3, dataset (Hook et al. 2012; MacCallum and Merchant 2012) (http://www.laketemp.net/home/) including Lakes Victoria, Tanganyika, and Malawi, and many others use a surface temperature of monthly nighttime estimates from a climatology over 1995-2012, otherwise for smaller lakes (typically for lakes of less than $50 \mathrm{~km}^{2}$ ) the value is prescribed from the nearest grid cell that is either in ARC-Lake or is an ocean grid cell. A uniform sandy soil is applied across the domain in both regional simulations. This choice is made to avoid introduction of rainfall biases related to unrealistic small-scale variability in soil properties (De Kauwe et al. 2013), particularly in the convection-permitting model. Full details of the soil property setup are provided in the model description paper (Stratton et al. 2018), but for our analysis here the experiment design provides a clean comparison of the effect of the higher resolution and representation of convection. Further details of the simulations are provided in the CP4A overview paper (Stratton et al. 2018) and East Africa evaluation paper (Finney et al. 2019).

\section{b. Convection-permitting regional model (CP4)}

This regional climate model has no convection parameterization (including no shallow convection parameterization), instead convection occurs explicitly based on the atmospheric equations of motion. Convection is possible without parameterization because of the high resolution used (4.5-km grid spacing at the equator). Although small-scale shallow convection will not be well resolved, several past studies have shown success of such coarse grid spacings over tropical continents (Marsham et al. 2013; Willetts et al. 2017; Kendon et al. 2019). Each model uses orography at its raw resolution, so this aspect is better resolved by the CP4 simulation. A moisture conservation scheme is applied to this simulation (Aranami et al. 2015), which generally acts to reduce precipitation extremes over the African domain as discussed by Stratton et al. (2018). The large-scale cloud scheme (Smith 1990) is that used in other convectionpermitting versions of the Unified Model. The cloud scheme diagnoses liquid cloud fraction and condensed water when the gridbox mean relative humidity exceeds a critical value. Ice water content is determined by the microphysics scheme, with cloud fractions then diagnosed (Abel et al. 2017). A higher vertical resolution is used than in the parameterized convection models. The vertical grid consists of 80 levels up to $38.5 \mathrm{~km}$, with higher resolution in the boundary layer and troposphere. For all analysis in this study, the CP4 data have been regridded using area-weighting to the N512 horizontal grid.

\section{c. Parameterized convection regional model (P25)}

A regional simulation with parameterized convection is used to compare against the convection-permitting simulation. This simulation has the same grid spacing as the global driving model (approximately $26 \mathrm{~km}$ in latitude by $39 \mathrm{~km}$ in longitude at the equator). The vertical grid consists of 63 levels up to $41 \mathrm{~km}$. The cloud scheme used by the model is the prognostic cloud scheme (PC2; Wilson et al. 2008) as used in the global driving model. The P25 model is similar to the global driving model but provides a better comparison to the $\mathrm{CP} 4$ simulation as it uses the same domain, land surface, and aerosol climatologies. The convective parameterization is that implemented in GA7 (Walters et al. 2019). The scheme is based upon a mass flux scheme (Gregory and Rowntree 1990) with several extensions (Walters et al. 2017).

\section{d. Future-climate model setup}

The global driving model has also been run for a future climate using the representative concentration pathway 8.5 for greenhouse gas concentrations for year 2100 , and this has been used to drive a future simulation with the CP4 and P25 models (Kendon et al. 2019). For future-climate SSTs, a $\Delta T$ is added to the current-climate observation-based SSTs (described in section 2a), with the same change used for the global model and both regional models. The $\Delta T$ is calculated on a gridcell and monthly basis as the climatological decadal mean change in SST between the end of the century and the present day from HadGEM2-ES global climate model simulations. As well as the above conditions, for the regional models, a $\Delta T$ is applied to lake surface temperatures calculated based on a fraction of the change in land grid cells in the vicinity of the lakes in the HadGEM2-ES simulations (further details are given below). Ozone and aerosol climatologies are not changed from the current-climate simulation. The set of changes described allows the isolation of changes generated from future greenhouse gas changes. 


\section{e. Prescribed lake surface temperature changes}

For each lake and climatological month, the following approach is used to calculate a future change to add to the current-climate observed lake surface temperatures. Before final use the values calculated were smoothed using a 3-month rolling average. The equation to calculate the lake temperature change is

$$
\Delta T_{\text {lake }}=\Delta T_{\text {land }}\left[k+(1-k) \frac{\Delta T_{\text {coast,sea }}}{\Delta T_{\text {coast,land }}}\right],
$$

where $\Delta T_{\text {lake }}$ is the $\Delta T$ applied to observed currentclimate lake surface temperatures, $k$ is a constant 0.75 , $\Delta T_{\text {land }}$ is the average value of surface air temperature changes over the CP4 lake grid cells interpolated from the land grid cells in the global driving model, $\Delta T_{\text {coast,sea }}$ is the average change in air temperature of coastal ocean grid cells between $15^{\circ} \mathrm{S}$ and $15^{\circ} \mathrm{N}$ in the simulation by the global driving model, and $\Delta T_{\text {coast,land }}$ is the average change in air temperature of coastal land grid cells between $15^{\circ} \mathrm{S}$ and $15^{\circ} \mathrm{N}$ in the global driving model. The only lake grid cells in the global driving model were over Lake Victoria, but the associated temperature changes were not considered to be reliable, so the values in these grid cells were replaced by averages over land grid cells in the vicinity of the lake.

The $k$ constant represents the weighting of the temperature change of surrounding land compared to temperature change of surrounding land adjusted by the simulated ratio of coastal ocean/land warming. For $k=1$, the lake temperature changes will be the same change as the surrounding land. A smaller value adds an inertial term associated with the ocean-land contrast. Here a small inertial term $(1-k)$ with weighting 0.25 is used that is based on recent evidence that many lakes may be currently warming as fast as neighboring land (O'Reilly et al. 2015), although this is yet to be substantiated by other studies. The exact value of $k$ is somewhat arbitrary, but nevertheless it is a reasonable choice given the little evidence currently available on the response of East African lake temperatures to climate change. Lake surface temperatures for P25 were aggregated from the CP4 changes described above so that the changes are consistent between the two simulations.

Climate models have a variety of approaches to simulating Lake Victoria water temperature changes, and several approaches are used in the regional Coordinated Regional Downscaling Experiment (CORDEX) models (Vanderkelen et al. 2018). Some models, such as Rossby Center Regional Atmospheric Model, version 4 (RCA4), Consortium for Small-Scale Modeling in Climate Mode (CCLM), and the Canadian Regional Climate Model, version 5 (CRCM5), use the Flake 1D lake model. The Regional Atmospheric Climate Model, version 2.2 (RACMO22T), parameterizes temperatures on the basis of deep soil temperature of the surrounding land. The Consortium for Small-Scale Modeling climate version of the Lokalmodell (CCLM4-8-17) interpolates sea surface temperature. This latter approach generally leads to cold biases and suppression of lake rainfall. In CORDEX simulations, the range of projections of Lake Victoria rainfall varies from decreases to increases (Vanderkelen et al. 2018), which may relate to their different representations of the lake. Some global climate models represent the lake surface as water, others as saturated soil or in some cases as land. In any case, many of these models struggle to resolve the lake and the neighboring mountains due to coarse grid spacings. Here we have used regional models that use satellite-observed temperatures for the present day and in future climate have applied a change that is a fraction of the simulated temperature change of land grid cells around the lake in the future simulation of the global parent model. This approach ensures a lake temperature that matches observations in present day and a plausible response of temperatures to climate change even though there is no lake model coupled to the atmospheric model.

\section{f. Satellite rainfall observation product}

Two satellite-based rainfall products are used to evaluate the model simulations. These are the Tropical Rainfall Measuring Mission (TRMM) Multisatellite Precipitation Analysis 3B42, version 7, and the Climate Prediction Center Morphing technique (CMORPH) product (Xie et al. 2017). As with the CP4 data, all satellite data have been regridded using area weighting to the N512 resolution in order to compare to the parameterized convection model. For clarity only the CMORPH results are shown in figures, since the results of the two products are similar. Where relevant we discuss the TRMM results in the text.

The CMORPH product uses precipitation estimates from passive microwave instruments and propagates these precipitation estimates using motion vectors, which are obtained from geostationary satellite infrared data. Timeweighted linear interpolation is applied between forwardand backward-propagated precipitation estimates. Here we used the bias-corrected CMORPH product, which has calibrated the satellite-based precipitation estimates to gauge station data (Xie et al. 2017). Data are provided on an 8-km horizontal grid and at 30-min intervals from 1998. Data from 1998 to 2006 have been used.

The TRMM product combines passive microwavebased estimates of rainfall from multiple polar-orbiting 
instruments with infrared-based rainfall estimates from geostationary satellites (Huffman et al. 2007). Bias correction is then applied to the estimates on the basis of monthly rain gauge data. Data are provided on a $0.25^{\circ}$ horizontal grid and at 3-hourly intervals from 1998. The observation years used to compare with model simulations are noted in the relevant figure captions.

\section{Methods}

\section{a. Composite analysis}

To understand the drivers of extreme rainfall, composites of 3-hourly data are used. These take rainy 3hourly periods $\left(>0.125 \mathrm{~mm} \mathrm{~h}^{-1}\right)$ during which the rain rate is between the 98.5th and 99.5th quantiles, calculated on a gridcell basis. The first 3 -h period is taken as 0000-0300 UTC, with three consecutive periods thereafter. Averages are then taken over total column water and vertically integrated vertical mass flux at these times. An average over the $1.5-\mathrm{m}$ specific humidity in the preceding 3-h period is also used.

\section{b. Clausius-Clapeyron analysis}

This work analyses three ratios in relation to the Clausius-Clapeyron (CC) scaling, as shown in the equation below. These are the "precipitation change compared with CC scaling," the "humidity change compared with CC scaling," and a residual change. We calculate CC scaling as the change in $1.5-\mathrm{m}$ saturation vapor pressure:

$$
\frac{\Delta_{\%} P}{\Delta_{\%} e_{\text {sat } 1.5 \mathrm{~m}}}=\frac{\Delta_{\%} q_{1.5 \mathrm{~m}}}{\Delta_{\%} e_{\text {sat } 1.5 \mathrm{~m}}} \times \frac{\Delta_{\%} P}{\Delta_{\%} q_{1.5 \mathrm{~m}}},
$$

where

$$
\Delta_{\%} X=100 \times \frac{X_{f}-X_{c}}{X_{c}}
$$

and $P$ is precipitation, $e_{\text {sat } 1.5 \mathrm{~m}}$ is the saturation vapor pressure at $1.5 \mathrm{~m}, q_{1.5 \mathrm{~m}}$ is specific humidity at $1.5 \mathrm{~m}, X$ represents each of the previous variables, $X_{c}$ is using data from the current climate, and $X_{f}$ is using data from the future climate. For the first results using total rainfall, the values are averages taken over all times. For the second results of the extreme rainfall metric, the precipitation is the 99th percentile of rainfall during wet 3-h periods, the saturation vapor pressure is the average over all times, and the specific humidity is the average of times in the $3 \mathrm{~h}$ preceding rainfall when the rain rate is between the 98.5th and 99.5th quantiles. This latter measure is used because it approximates the humidity available to the storm. A comparison is still made to the all-time average (as opposed to the prestorm average) saturation vapor pressure to establish whether prestorm humidity changes relative to mean temperature change of location following CC scaling, or with a sub- or superscaling. By using different timings, the results will encompass differences in temperature at prestorm times relative to mean temperature, as well as changes in relative humidity at prestorm times.

\section{Future rainfall changes}

As a starting point, Fig. 1 shows the total rainfall, rainfall frequency, average rain rate, and 99th percentile rain rate during wet 3 -h periods (i.e., an extreme-rainrate metric). The two models show broadly the same distribution of total rainfall, and the details of differences are discussed at length in Finney et al. (2019). Average and extreme rain rates are much lower in the P25 model, and rainfall frequency is much higher. Kendon et al. (2019) show that, for wet season equivalents of these metrics, CP4 is close to the TRMM and CMORPH rainfall estimates, while P25 underestimates rain rates and overestimates rainfall frequency. Such biases are generally expected in models using parameterized convection and were also found for the specific whole-year metrics analyzed here (not shown).

Although the parameterized convection model has biases in certain current-climate rainfall metrics, it is common to still consider the climate change signal projected. In this study, we investigate whether the projections of climate change in rainfall differ between the parameterized convection model, and the model using explicit convection. Given the different current-climate values for rain rates and frequency, we use future percentage changes relative to their own current-climate values to compare the models.

The two simulations analyzed here each exhibit large spatial variability of changes in rainfall characteristics, as well as substantially different projections of certain metrics (Fig. 2). Figure 2 includes significance testing where hatching shows insignificant grid cells at $5 \%$ level from a Student's $t$ test applied over the 10 annual values of the metrics. We assume that the 10 annual values in each of the current- and future-climate simulations are independent, even though there is common interannual variability in the SST forcings used. The results show that $\mathrm{CP} 4$ gives a stronger response of total rainfall than P25 (gradient of the best-fit line $m=1.28$ ), with large increases in many drier regions, although overall spatial patterns of changes are similar (correlation coefficient $R=0.71$ ). Both models show notable percentage increases over Lake Victoria (label V) and surrounding mountains, especially to the northeast; the Turkana channel $(\mathrm{T})$; the center of the Horn of Africa $(\mathrm{H})$; and 

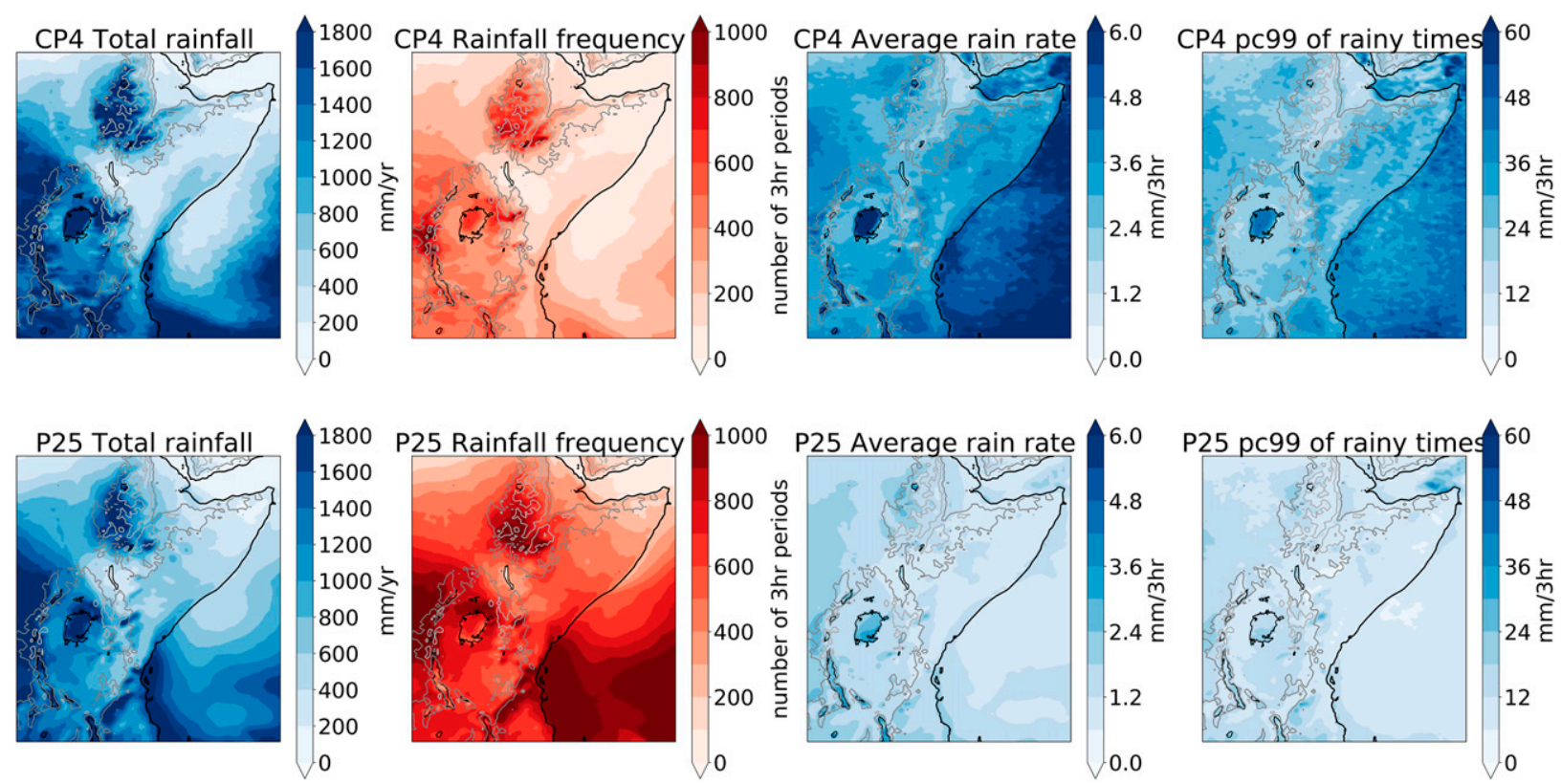

FIG. 1. Current-climate annual climatology of rainfall metrics for (top) CP4 and (bottom) P25. Rainfall metrics shown are the (left) total rainfall, (left center) frequency of 3-hourly rainfall, (right center) average rain rate at wet 3-h periods, and (right) 99th percentile of wet 3-h periods. Wet 3-h periods are 3-hourly rainfall $>0.125 \mathrm{~mm}(3 \mathrm{~h})^{-1}$. Gray contours show 1000- and 2000-m orography.

the Awash Valley (A), with relatively small changes close to the coast.

CP4 shows similar increases across the domain in both average and extreme rain rates, while P25 shows large variations in the increases, for example, ranging from $10 \%$ to over $90 \%$ increases over the Horn of Africa. The spatial pattern of changes of P25 mirror the changes in total rainfall, whereas the spatial pattern of CP4 rain rate changes are not similar to the total changes, resulting in very low correlations $(\sim 0.1)$ between the two models. Changes in rainfall frequency are correlated between models $(R=0.74)$ but with much larger changes in CP4 $(m=1.66)$. P25 does not capture such large percentage changes in rain frequency, and therefore, its pattern of changes in rain intensity and total rainfall are broadly similar.

In summary, within the current climate the two models have similar total rainfall, despite large differences in average rain rate, rainfall frequency, and extreme rain rates. The CP4 model shows larger increases in total rainfall than P25 under climate change, but the spatial patterns of change are similar. However, the spatial patterns and magnitudes of change of other metrics are much more different between the models. It is notable that, on a gridcell basis, some of the largest increases in extreme rain rate are in the P25 model. On average, it is expected that larger changes would be seen in an explicit convection model, and this is the case for many grid cells. However, the focus of the large changes in the P25 model around areas where mesoscale flows dominate (Lake Victoria basin, the Horn of Africa, and the eastern Congo) suggests this is just an intensification of those underlying mechanisms. In contrast, in the CP4 model, the increases are widespread and show that in this model, with a much better representation of convection, climate change affects storms more broadly across the region than the parameterized convection model suggests.

\section{Drivers of rainfall change}

Availability of water and convective available potential energy provide the fundamental controls on convection and rainfall, and in the tropics these are affected by the Hadley and Walker overturning circulations. We first consider the horizontal flows of moisture moving water vapor from the ocean across the continent. Figures $3 \mathrm{a}$ and $3 \mathrm{c}$ show that both models have an average easterly flow of moisture flux from the Indian Ocean across eastern Africa. In the future scenario, both models project this flow will increase (Figs. 3b,d). The moisture flux convergence correspondingly increases over the land too, generating increased rainfall. Similar analysis has been undertaken for evaporation (not shown), the other source term in the atmospheric moisture budget (Finney et al. 2019). Evaporation over water bodies increases with increased temperature, thereby increasing the source of moisture to the atmosphere in these locations. There are also some small changes/differences in evaporation over land, but these are generally smaller than, and in 

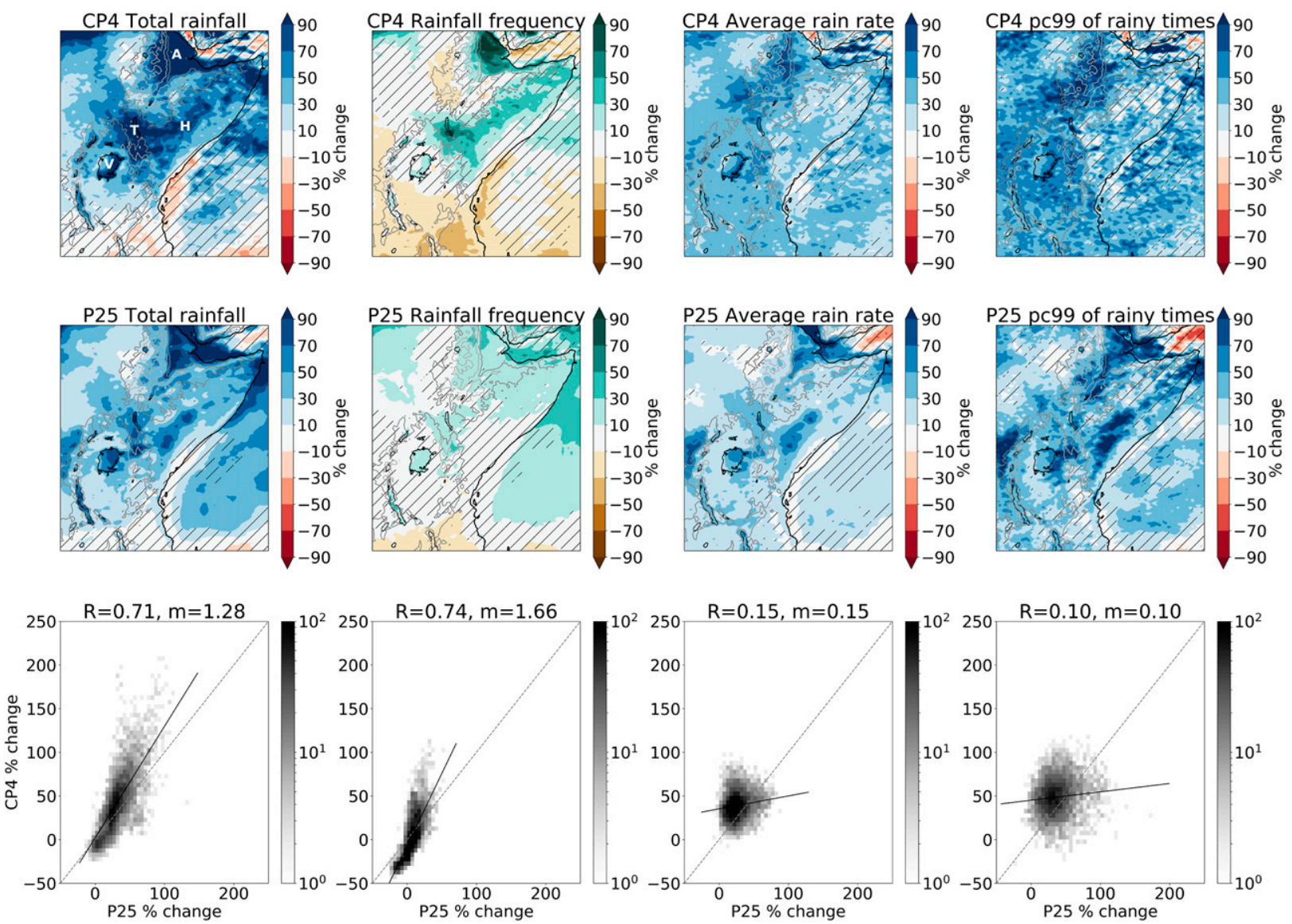

FIG. 2. Percentage changes in the annual climatology of rainfall metrics for (top) CP4 and (middle) P25, and (bottom) the relationship between the projections of the two models. Rainfall metrics shown are the (left) total rainfall, (left center) frequency of 3-hourly rainfall, (right center) average rain rate at wet 3-h periods, and (right) 99th percentile of wet 3-h periods. Wet 3-h periods are 3-hourly rainfall $>$ $0.125 \mathrm{~mm}(3 \mathrm{~h})^{-1}$. Hatching shows insignificant grid cells at the $5 \%$ level as based on a Student's $t$ test applied over the 10 annual values of the metrics. Density plots are shown for land and lake grid cells in the maps, but ocean grid cells have been excluded. Pearson's correlation coefficient $R$ and the gradient of the black best-fit line $m$ are given. Gray contours show 1000- and 2000-m orography. The white letters V, $\mathrm{T}, \mathrm{H}$, and A in the top-left panel label Lake Victoria, the Turkana Channel, the Horn of Africa, and the Awash Valley.

most cases less than one-half of, the moisture flux convergence changes/differences shown in Fig. 3.

A subtlety in the moisture flux changes is that there is actually weaker easterly flow in the CP4 model (Fig. 3e), as well as weaker increases (Fig. 3f), relative to the P25 model. Potentially as a response to this smaller easterly flow increase, the CP4 model shows larger rainfall increases than the P25 model in the East African Rift Valley but smaller changes over eastern Congo (Fig. 2). This result clearly demonstrates how changing the representation of convection modifies the effect of climate change on continental-scale rainfall patterns and circulations.

Such westerly anomalies enhancing rainfall over the Lake Victoria region are also presented by Giannini et al. (2018). In their conclusions, Giannini et al. (2018) caveat that the complex orography of East Africa is likely to affect this anomalous westerly flow and that the global models used may not sufficiently resolve this for the result to be robust. However, in our results, the model with the highest resolution exhibits the westerly moisture flux anomaly relative to the lower-resolution model, and therefore we suggest the results of Giannini et al. (2018) are not simply a consequence of poor representation of orography.

In Fig. 4, the annual average column-integrated vertical mass flux, and change in the future climate are shown. The current-climate results show both models have net ascent over the highland areas of eastern Africa, and net descent over the lowland areas of the Horn of Africa (Figs. 4a,c). Ascent and descent generally correspond to the wetter and drier regions, respectively. Figure 4 demonstrates how East Africa is a region of transition from ascent in the Congo to subsidence over the Indian Ocean, with these ascents and descents being part of the tropical 
a) CP4 moisture flux current

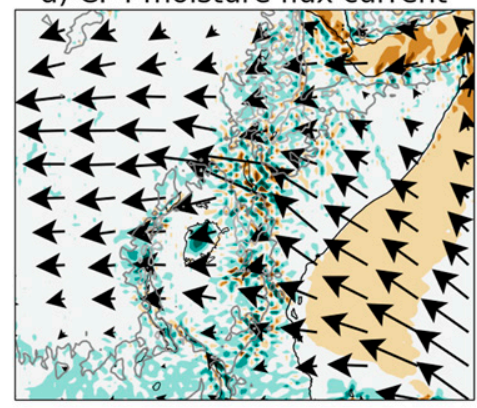

C) P25 moisture flux current

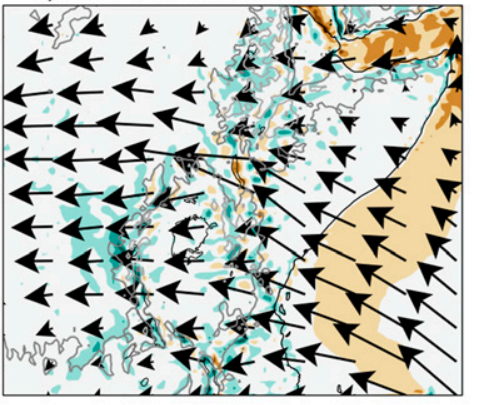

e) CP4 - P25 current

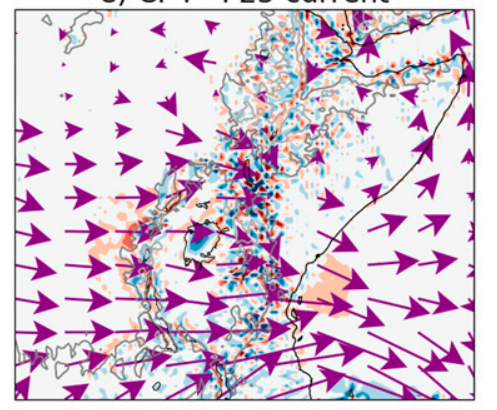

b) CP4 moisture flux change

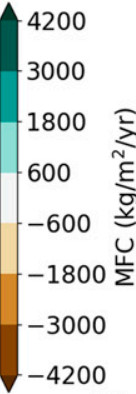

$\stackrel{30}{\rightarrow} \mathbf{1 0}^{8} \mathbf{k g} / \mathrm{m} / \mathrm{yr}$

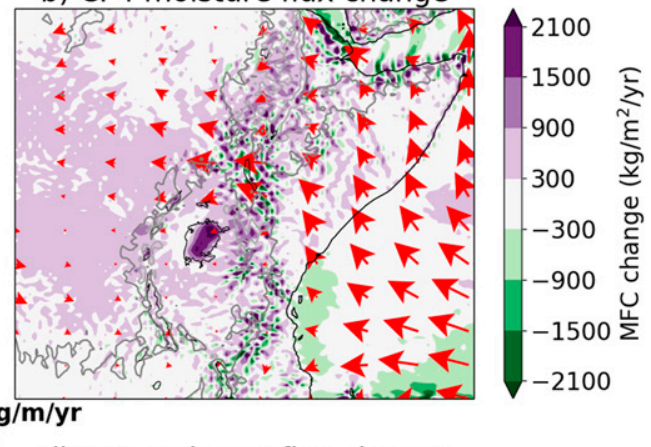

d) P25 moisture flux change
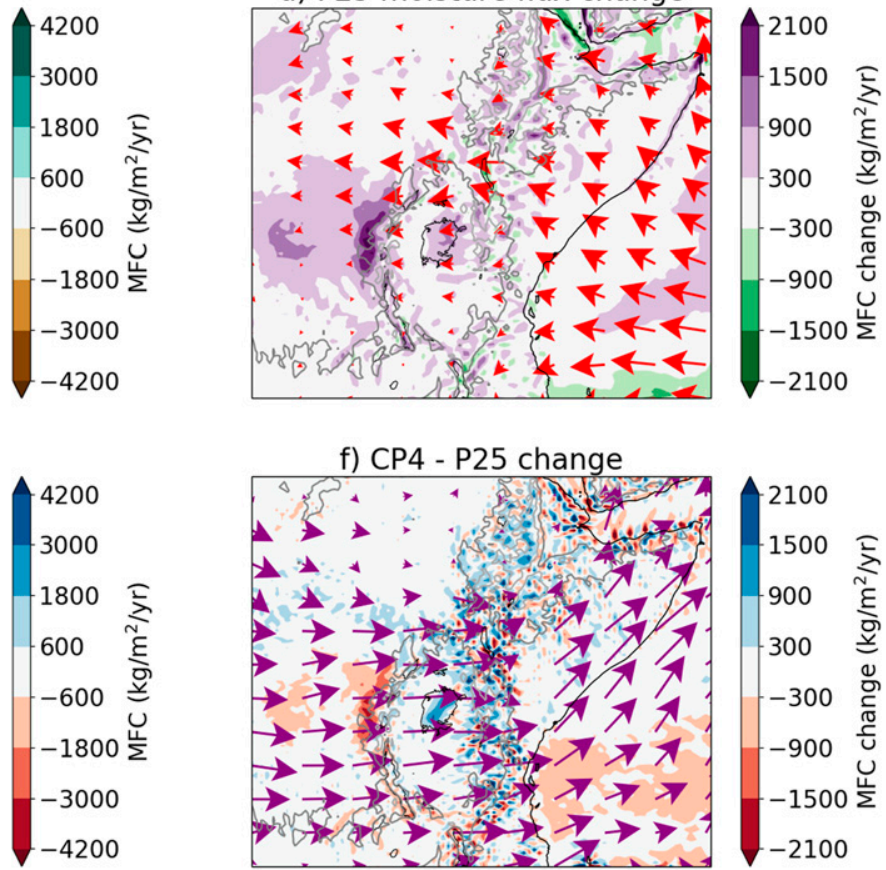

f) CP4 - P25 change

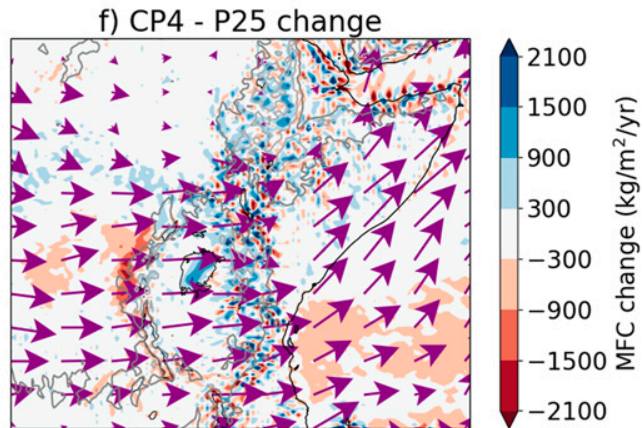

$-2100$

\section{$5 \times 10^{8} \mathrm{~kg} / \mathrm{m} / \mathrm{yr}$}

FIG. 3. Average moisture flux (vectors) and moisture flux convergence (color-shaded contours) for (left) current climate and (right) future change for (top) CP4 and (middle) P25. The moisture flux variable is a column integral over the all model levels up to full model height and weighted by density. Also shown are (bottom left) differences between CP4 and P25's current climate and (bottom right) the difference between the models' climate change response. Gray contours show 1000- and 2000-m orography.

climate features of the Hadley and Walker circulations. It is, therefore, of interest to understand how the two models here respond to the influence of climate change on these circulations and how they modify them on a regional scale. In general, tropical overturning circulations are expected to weaken under climate change (Collins et al. 2013). And indeed, over eastern Africa, there is reduced subsidence in the regions of net subsidence. However, there is also increased ascent in regions of net ascent, thereby also generating increased rainfall in these regions and demonstrating an important difference between eastern African climate change response and the theoretical global average view of the response of the overturning circulation.

To improve understanding of drivers of modeled rainfall changes, and therefore our confidence in projections, it is common to consider the well-studied thermodynamic result of increasing saturation vapor pressure $e_{\text {sat }}$ with increasing temperature of $\sim 6 \% \mathrm{~K}^{-1}$ near the surface (CC scaling) (O'Gorman and Muller 2010; Kendon et al. 2019). Global average rainfall is expected to increase at a sub-CC scaling $\left(1 \%-3 \% \mathrm{~K}^{-1}\right)$ (Collins et al. 2013). However, this will vary regionally, especially over land where advection of moisture from the oceans is an important factor. 
a) CP4 current
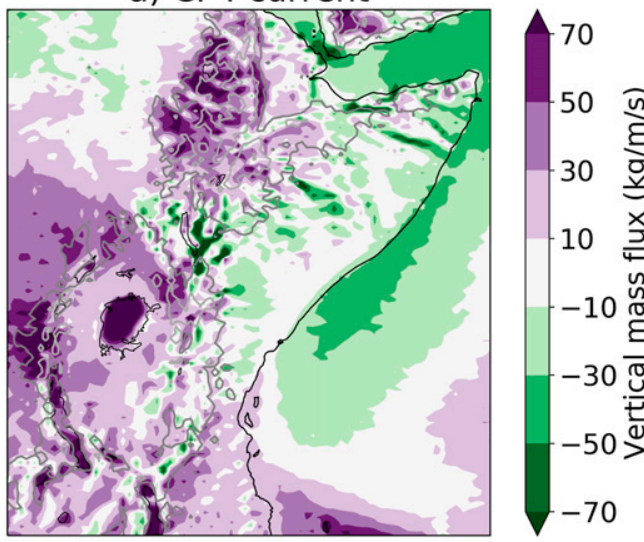

c) P25 current
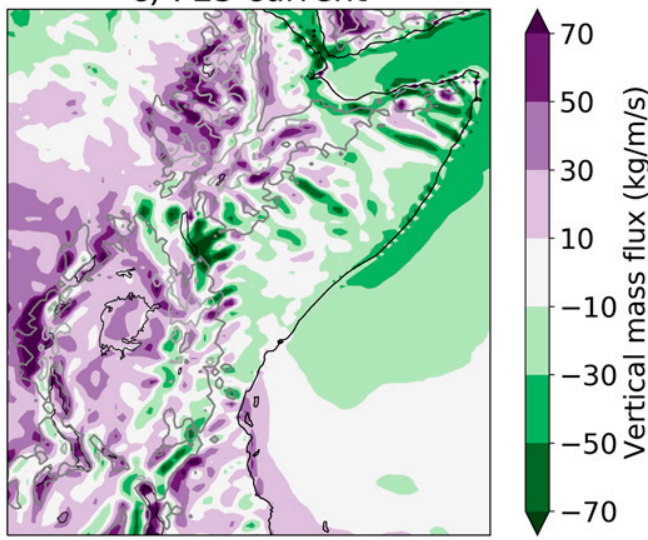

b) CP4 change

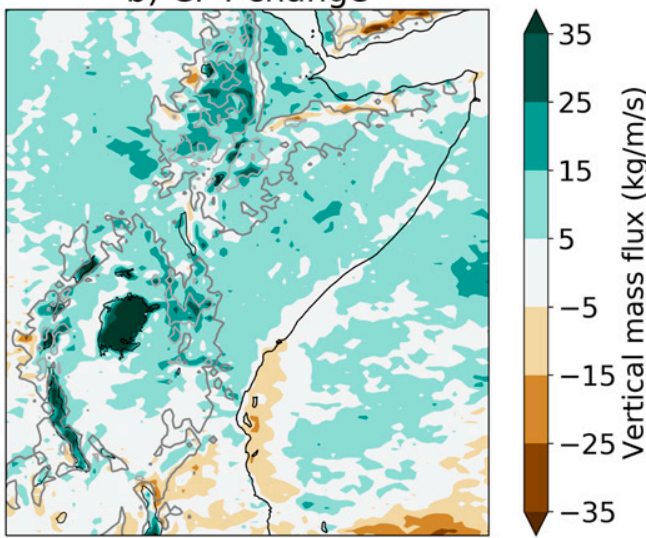

d) P25 change

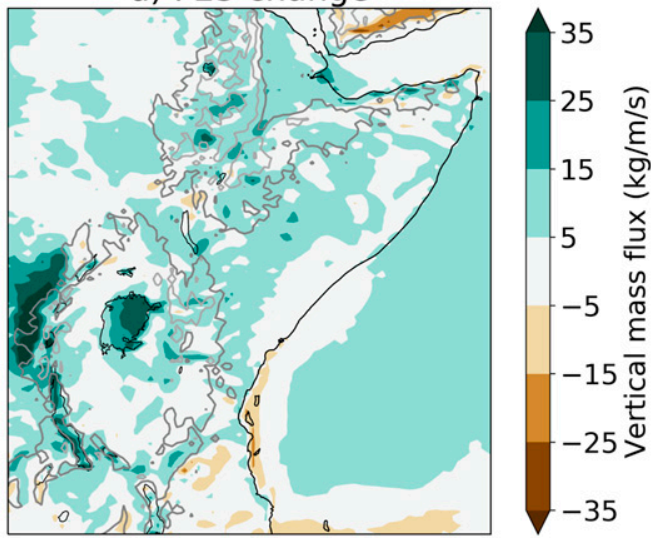

FIG. 4. Average column-integrated vertical mass flux for (top) CP4 and (bottom) P25 for (left) current climate and (right) future change. Gray contours show 1000- and 2000-m orography.

Figures 5a and 5d show that over much of eastern Africa total rainfall increases at a super-CC scaling, deviating from the global average behavior. This is despite specific humidity over those areas roughly following CC scaling (i.e., relative humidity is unchanged). Since changes in specific humidity do not account for the super-CC and subCC scalings of rainfall (Figs. 5b,e), they must occur as a result of changes in rainfall per change in low-level specific humidity (Figs. 5c,f), generally corresponding to changes in vertical mass flux (Fig. 4). The increase in moisture flux convergence (Fig. 3) also supports the increase in rainfall. The two models show similar patterns of change, but $\mathrm{CP} 4$ shows larger changes. It should be noted that the average vertical mass flux change in Fig. 4 includes changes in subsidence as well as changes in ascent. Since the strength of subsidence may not have a proportional effect on rainfall, a direct correspondence between average vertical mass flux and total rainfall is not expected. However, it is useful to see that the changes are broadly consistent.
The result that total rainfall changes are strongly controlled by the rainfall per humidity change implies one or a combination of different mechanisms: 1) increased frequency of storms in the future climate, 2) a speeding up of the water cycle through increased evaporation and/or moisture flux convergence to accompany increased updraft strength and supply moisture at a faster rate to storms, or 3) a greater conversion of available moisture to rainfall within clouds through climate change impacts on storm dynamics and microphysics. We have shown in Fig. 2 that frequency of rainfall increases, demonstrating that mechanism 1 is a factor. To establish the role of mechanism 3 would require much more detailed analysis beyond the scope of this study. However, we can provide further insight on the role of mechanism 2 through focusing on the extreme rainfall cases.

Figure $5 \mathrm{j}$ shows that for many places parameterized convection does not capture the super-CC changes in extremes in the CP4 model (Fig. 5g). Instead we see that 


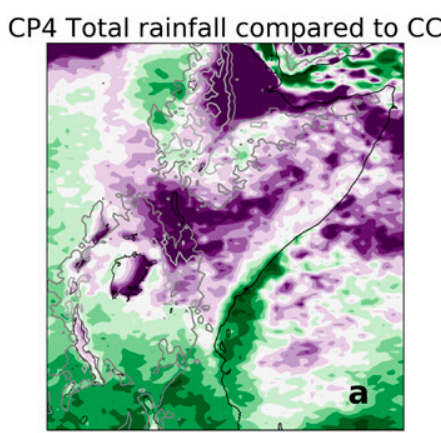

P25 Total rainfall compared to CC
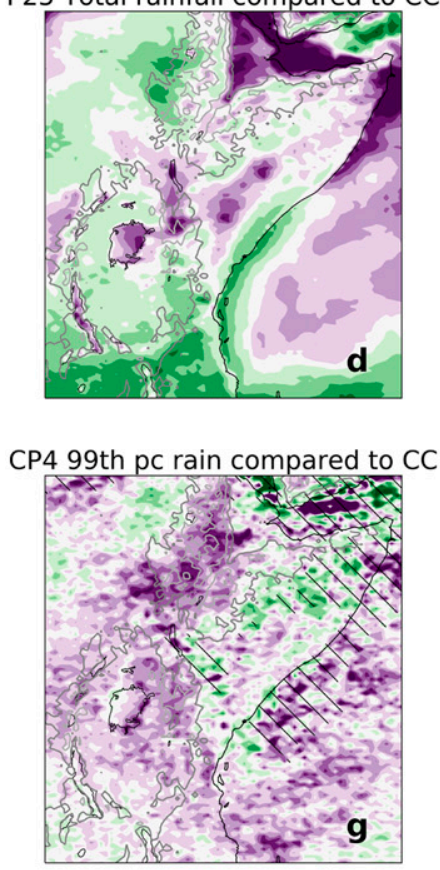

P25 99th pc rain compared to CC

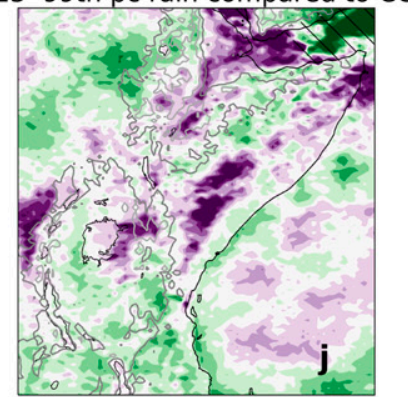

CP4 Humidity change compared to CC

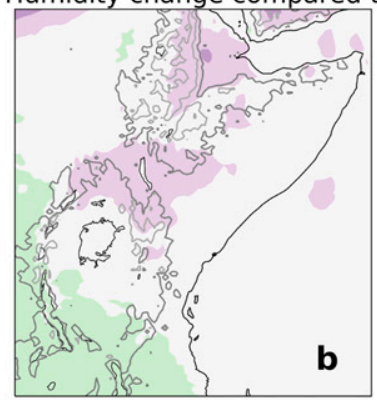

P25 Humidity change compared to CC

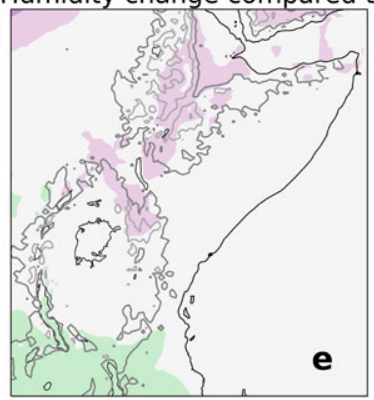

CP4 preceding humidity compared to CC

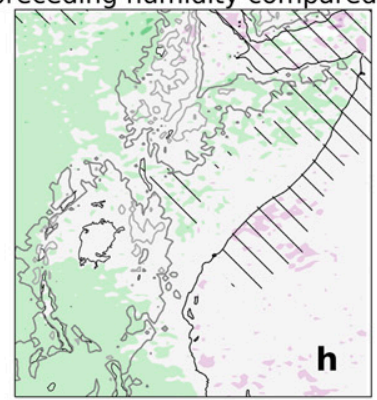

P25 preceding humidity compared to $\mathrm{CC}$

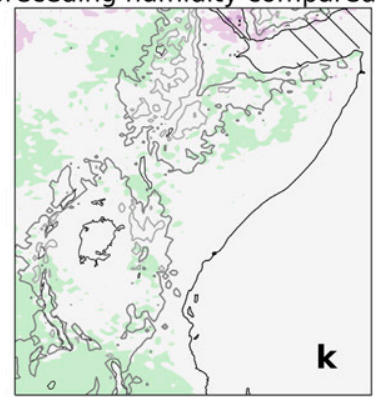

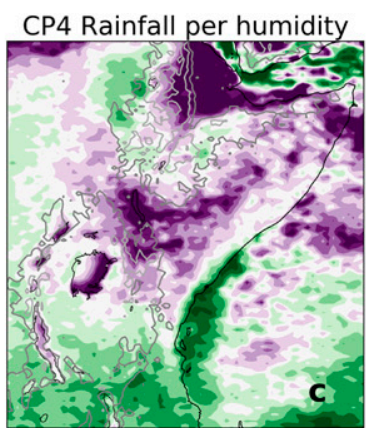

P25 Rainfall per humidity

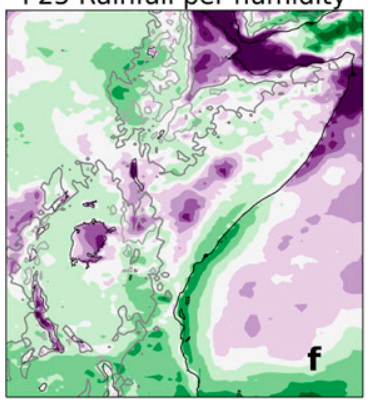

CP4 99th pc rain per humidity

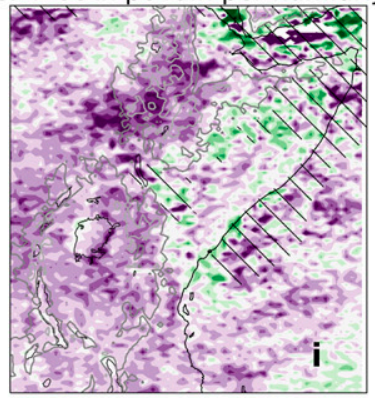

P25 99th pc rain per humidity

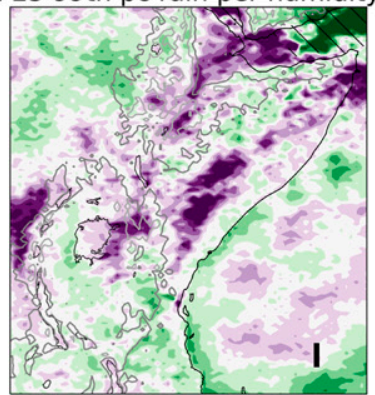

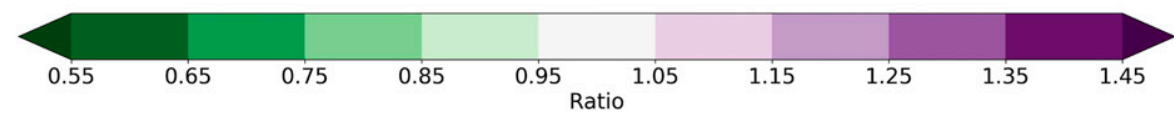

FIG. 5. Clausius-Clapeyron scaling of rainfall and its decomposition into a humidity change and a residual change: (left) ratio of rainfall change to $e_{\text {sat }}$ change, (center) ratio of specific humidity change to $e_{\text {sat }}$ change, and (right) ratio of rainfall change to specific humidity change for (a)-(f) total rainfall using average humidity over all times and (g)-(l) the 99th percentile of rainfall at wet times using humidity from the $3 \mathrm{~h}$ preceding extreme rainfall. Hatching in (g)-(1) shows where fewer than 10 rainfall events have been used in either/both of the current- and future-climate composites. Gray contours show 1000- and 2000-m orography. For details of the methods of composition and Clausius-Clapeyron analysis refer to section 3. 

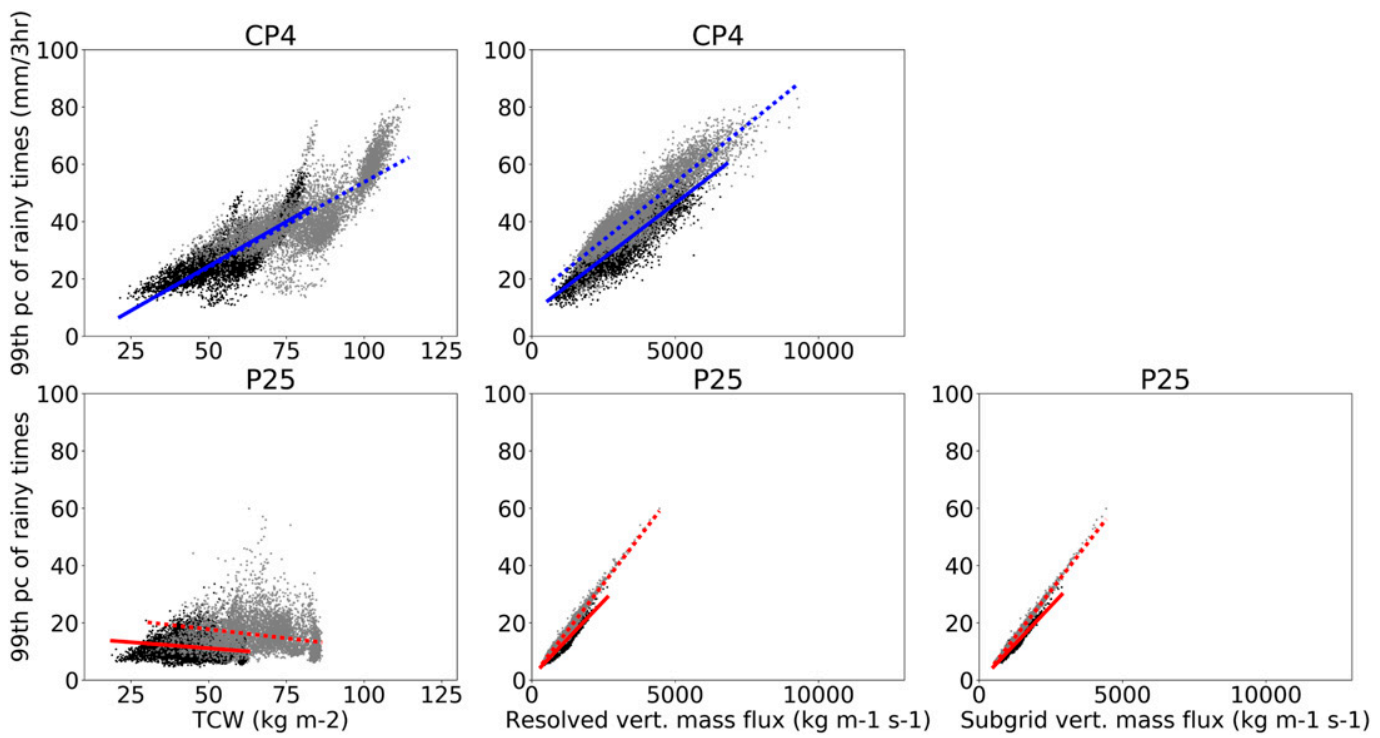

FIG. 6. Composited TCW and column-integrated vertical mass flux at times for which rainfall is between the 98.5th and 99.5th percentiles of wet times $\left[>0.125 \mathrm{~mm}(3 \mathrm{~h})^{-1}\right]$. Black dots are current-climate land grid cells, and gray dots are future-climate land grid cells. Grid cells with fewer than 10 contributing events are not included. Solid lines show the current-climate line of best fit, and dashed lines show the future-climate line of best fit.

the largest increases occur over the Horn of Africa (Fig. 5j) in similar locations to where largest total rainfall increases occur (Fig. 5d). CP4, however, shows a very different response of extremes (Fig. $5 \mathrm{~g}$ ) compared to its total rainfall changes (Fig. 5a). The super-CC scaling is a result of factors other than low-level humidity, since available humidity preceding the extreme rain events increases at $\mathrm{CC}$ scaling or less (Fig. 5h). The $\mathrm{CC}$ scaling of humidity will have contributed toward part of the increase of rain rate, but the vertical mass flux can also further increase the rain rate beyond the $\mathrm{CC}$ scaling. Analysis of the total column water (TCW) and vertical mass flux at times of extreme rainfall confirms that the parameterized convection has a weaker sensitivity to spatial variability of TCW (Fig. 6) and has a smaller range in both TCW and vertical mass flux. Both models do show increased values of updraft mass flux in the future, suggesting the super-CC scalings of total rainfall are not solely a result of increased rainfall frequency but also these stronger updrafts. There is evidence in the literature that storms modify the available moisture of the environment (Taylor et al. 2017). Therefore, a smaller range of TCW and updraft mass flux, relative to the $\mathrm{CP} 4$ model, highlights that the P25 model fails to sufficiently modify its environment during the lifetime of a storm, thereby limiting the highest values of 1) available water and 2) updraft strength driven by latent heating.

\section{Changes to mesoscale circulations}

We now consider changes over Lake Victoria and the Horn of Africa, both areas of super-CC total rainfall change (Figs. 5a,d) and containing key population centers (e.g., Kampala, Uganda, and Mombasa, Kenya). There is significant influence of lakes and the Indian Ocean on rainfall in eastern Africa. Contrasts between water and land in daily cycles of temperature lead to mesoscale flows that drive convergence and convection. Under climate change there are lags in the surface warming of water due to mixing that can suppress or enhance the underlying daily cycles of mesoscale flows. In the simulations here, the surface temperature changes of lakes and oceans are imposed based on global climate models and understanding of how lake bodies may respond to climate change (see section 2 for details). The temperatures changes at 1200 and 0000 UTC and the average change are shown in Fig. 7. The results show that the land warming is greater than water warming. In the daytime, when land is warmer than water, the temperature contrast between the two surface types increases under climate change. While at nighttime, when land is cooler than water, the temperature contrast will decrease under climate change. These different changes in temperature contrast are important for mesoscale circulations and are discussed in the following sections. Note that for the remainder of this section times are given in East Africa time (EAT), which is UTC plus $3 \mathrm{~h}$. 

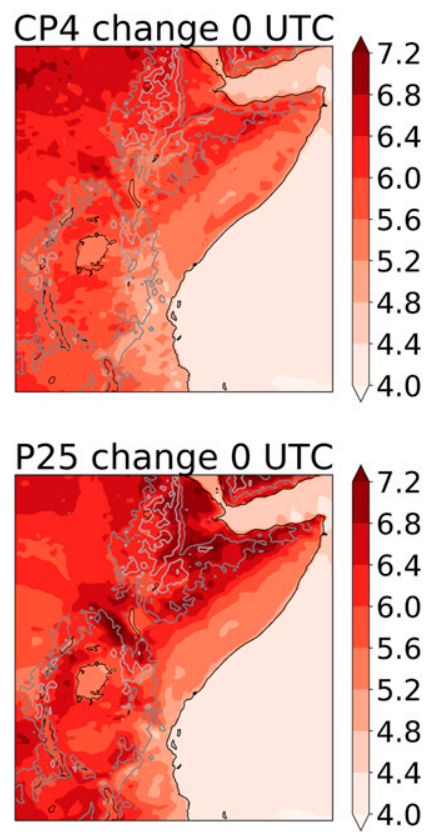
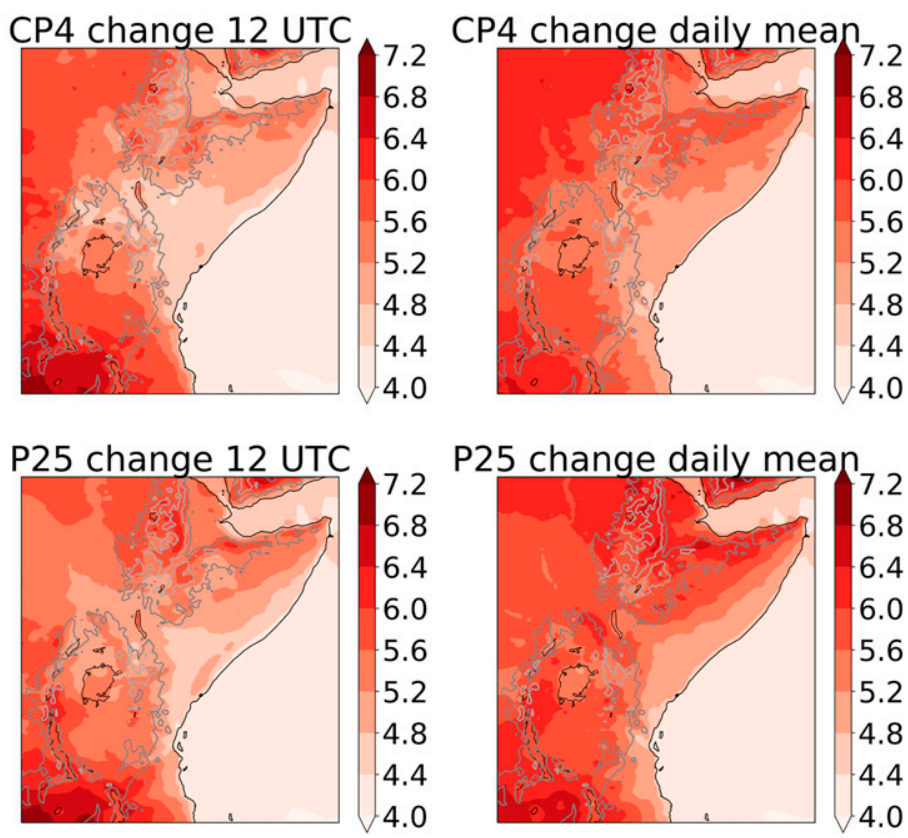

FIG. 7. Average 1.5-m temperature future change (K) at (left) 0000 UTC, (center) 1200 UTC, and (right) all times for (top) CP4 and (bottom) P25. Gray contours show 1000- and 2000-m orography.

\section{a. Nocturnal land-breeze convergence over Lake Victoria}

Lake Victoria is Earth's largest tropical lake, a source of the Nile, and a key natural resource. The lake rainfall, which maintains the lake, is generated by low-level convergence over the lake at night as a consequence of the lake-land temperature contrast (Anyah et al. 2006; Thiery et al. 2015; Williams et al. 2015; Finney et al. 2019) as captured by both models (Fig. 8). The total convergence across the lake is $0.00106 \mathrm{~s}^{-1}$ in P25 and $0.00120 \mathrm{~s}^{-1}$ in $\mathrm{CP} 4$, so a stronger land-breeze forcing occurs in the CP4 model as discussed by Finney et al. (2019). The CMORPH satellite estimates of rainfall confirm the nighttime peak in rainfall, though the rainfall maximum is offset slightly to the west of the model rainfall maximum. The same analysis has been performed with an alternative satellite rainfall product, TRMM (not shown). The TRMM product also shows a lake maximum of nocturnal rainfall but this is over the southwest of the lake. The difference between satellite products in the exact location of the maximum suggests the models cannot be evaluated to this level of detail, but it can be said that they correctly simulate a nighttime peak in rainfall over the lake (Finney et al. 2019).

Increases in atmospheric moisture under climate change lead to an increase in rainfall over the lake, but this is modified by changes to the nighttime convergence. Under climate change land warms more than water. At night this leads to a weaker lake-land temperature contrast (Fig. 7) and weaker convergence (Fig. 8). Both models simulate similar reductions in lake convergence, $-16 \%$ in $\mathrm{P} 25$ and $-13 \%$ in CP4. Correspondingly, both models show smaller percentage increases in rainfall where that convergence has weakened, resulting in the largest percentage rainfall increases over the east and south of the lake. Contrasting east-west changes have also been found previously (Thiery et al. 2016), and the success of the P25 simulation here gives confidence that parameterized convection models may be able to qualitatively capture the pattern of mean rainfall changes over Lake Victoria. However, such success is reliant on the simulations using high enough resolution to represent the lake and capture changes in lake temperature (which are imposed here). Nevertheless, with both our study and a past study showing an east-west contrast in precipitation change, those carrying out future impact studies should consider that communities on the eastern shore of the lake may face larger percentage increases in rainfall than on the western shore. Future ensemble convection-permitting projections in the Lake Victoria basin, such as those of the climate Extremes in the Lake Victoria Basin (ELVIC) project, will be able to further establish the robustness of this result.

We have demonstrated the important role of convergence over Lake Victoria on rainfall and its future change. This convergence arises due to the lake-land temperature contrast, and as a result is a function of the change in that contrast. The supplemental material of 

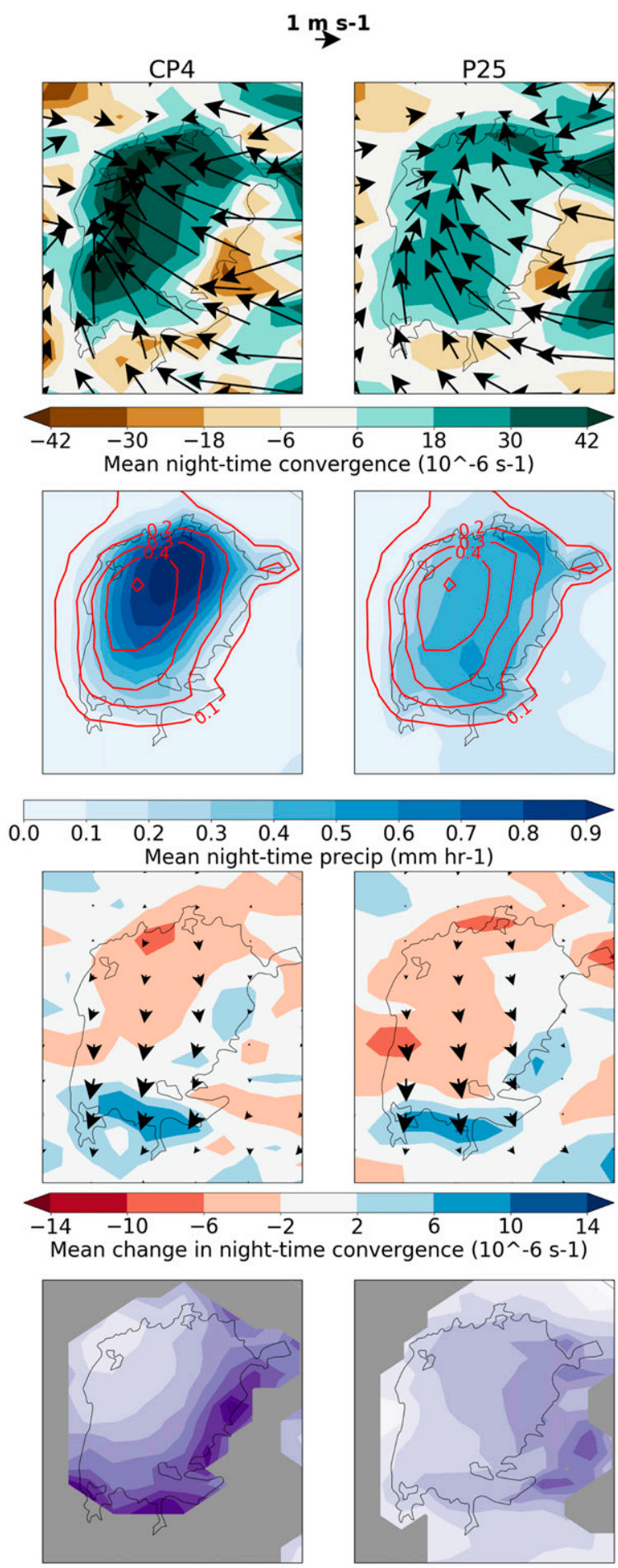

$\begin{array}{llllllllll}0 & 20 & 40 & 60 & 80 & 100 & 120 & 140 & 160 & 180\end{array}$

Percentage change in night-time hourly precip (\%)

FIG. 8. Rainfall, 10-m wind, and 10-m wind convergence changes over Lake Victoria averaged over 0000-0900 EAT for (top),(top middle) current climate averages and (bottom middle),(bottom) future climate changes. The red contours are CMORPH rainfall observations. Gray shading masks areas with $<0.1 \mathrm{~mm} \mathrm{~h}^{-1}$ rainfall in the current climate.
Thiery et al. (2016) shows an increase in mean 2-m air temperature of Lake Victoria of 3.5-4 K using RCP8.5 2071-2100, with mean temperature increases of land around the lake of about $3.5-4.5 \mathrm{~K}$. Mean $1.5-\mathrm{m}$ temperature changes from the simulations here are shown in Fig. 7 , these are substantially greater (lake: $5.4 \mathrm{~K}$; CP4 land: up to $6.0 \mathrm{~K}$; P25 land: up to $6.4 \mathrm{~K}$ ), but overall change in the mean lake-land temperature contrast is similar to that of the previous study $(\sim 0.5-1 \mathrm{~K})$. Figure $5 \mathrm{~b}$ shows that in CP4 the low-level moisture over the lake is scaling with the temperature increase following the CC relationship, and this could be expected of the model of Thiery et al. (2016) too. The higher temperature increase in CP4 than in Thiery et al. (2016) has likely led to a higher moisture availability and may explain why our model results show an increase in average rainfall over the lake while the previous study results show a decrease in mean lake rainfall, that is, with a greater warming the scaling of available water $\left(\sim 7 \% \mathrm{~K}^{-1}\right)$ may dominate the decreased convergence from decreasing nocturnal landlake contrast. This hypothesis would need dedicated runs with varied lake warming to test. Our results, however, appear to show that the parameterization of convection does not change the fundamental character of climate change in Lake Victoria total rainfall, likely since the rainfall is strongly forced at night and so is not directly affected by the diurnal timing bias of the daytime parameterized convection, unlike the evening rainfall coupled to the sea breeze discussed in the next section.

\section{b. Sea-breeze convergence over the Horn of Africa}

The Horn of Africa is an unusually dry tropical region, particularly vulnerable to catastrophic droughts (Funk et al. 2019), where convergence of low-level moisture from the sea breeze, that arises from the land-ocean temperature contrast, provides a strong control on rainfall. A transect was chosen to capture the convergence and rainfall patterns along the Horn of Africa, as well as the patterns of change in those features. Consideration was also given to the clarity of the propagating rainfall feature in the CMORPH satellite rainfall estimates. The hourly average values for $10-\mathrm{m}$ wind convergence and rainfall were interpolated to points along the transect, and then plotted as Hövmöller plots in Fig. 9. The transect from the coast toward the Ethiopian highlands in Fig. 9 shows that both models have an inland progression of low-level convergence through the afternoon and evening because of the sea breeze. Both models also show a stationary nighttime convergence between $0^{\circ}$ and $1^{\circ}$ latitude. This is located along the coastline and associated with the mean onshore flow of the Somali low-level jet being slowed as it passes from the relatively smooth ocean to the coarser land. 

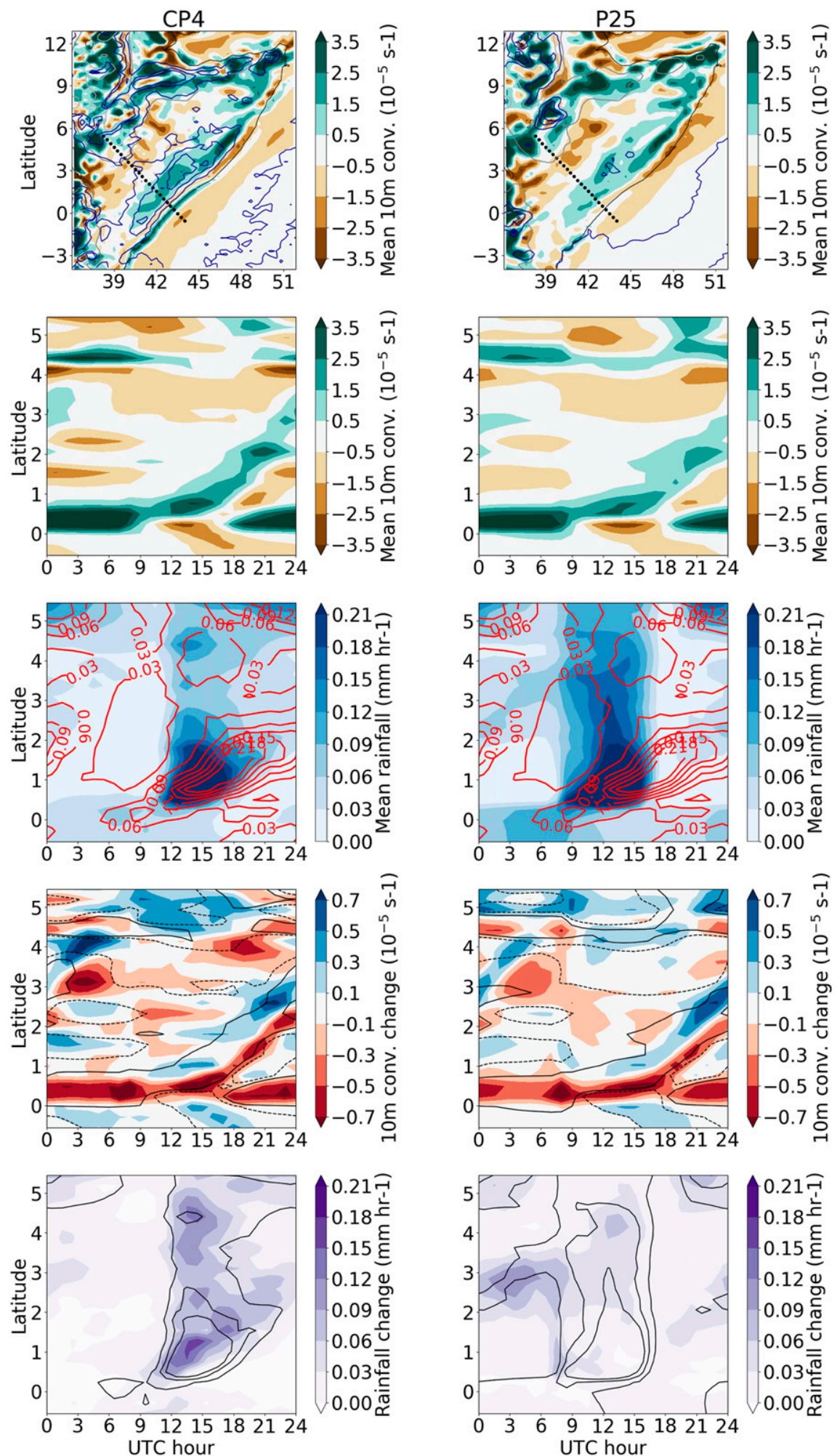

FIG. 9. Transect Hövmöller plots of rainfall and dynamical changes over the Horn of Africa for (left) CP4 and (right) P25: (top) mean 1800 EAT 10-m wind convergence and rainfall (blue contours), along with the black dotted transect used in the other panels; (top middle),(middle) current climate means, where the red contours are CMORPH rainfall observations, and (bottom middle),(bottom) mean changes under future climate, where solid and dashed black contours show positive and negative values, respectively, from the current climate. 
Satellite rainfall estimates of CMORPH (red contour) show a feature in the mean rainfall that propagates inland with the sea-breeze convergence-something that is much better captured by $\mathrm{CP} 4$. The satellite rainfall product of TRMM also shows a similar propagation of rainfall to CMORPH (not shown). The CP4 model does show an overestimate, though smaller than P25, of rainfall inland $\left(\sim 3^{\circ}\right.$ latitude; 1500 EAT) but shows an inland rainfall progression through the afternoon, whereas P25 rainfall completely cuts off at 1800 EAT when rainfall observations are peaking. Our results support similar findings by Birch et al. (2015) that parameterized convection simulations are able to produce the sea breeze, but not a realistic response of convection and rainfall.

In general, increased specific humidity under climate change (i.e., close to unchanged relative humidity shown in Fig. 5 with increased temperatures shown Fig. 7) will work to increase rainfall, and this rainfall increase is seen in both models in Fig. 9. However, changes in convergence are also likely to affect generation of rainfall through increased likelihood of triggering convection and increased supply of moisture to storms. The greater landocean contrast in the future (Fig. 7) strengthens the sea breeze in both models, giving greater convergence along the leading edge, accompanied by weaker convergence on the trailing edge, resulting in the convergence line initiating farther inland (Fig. 9; 1200-1500 EAT and $\sim 0.5^{\circ}$ latitude). In P25, rainfall only responds at night, whereas the $\mathrm{CP} 4$ rain responds throughout the afternoon, with the exception being close to the coast where the convergence line begins farther inland. This is particularly important for densely populated areas of the coastline, including those in major cities such as Mombasa and Mogadishu, Somalia. Under climate change this coastline region may experience weaker increases in rainfall than farther inland or even no change in total rainfall (Fig. 2), something not well simulated with parameterized convection. Furthermore, global climate models with much coarser resolution than P25 would not be able to capture the small-scale but important sea breeze.

\section{Conclusions}

We highlight three main conclusions:

1) For total rainfall change over the Lake Victoria region, there is uncertainty from the parameterization of convection in a regional model, which shows smaller changes over the region when compared with the explicit simulation but larger changes over the eastern Congo basin. These differences between the Congo and Lake Victoria regions are associated with westerly anomalies of zonal moisture flux and its future changes in the convection-permitting model relative to the parameterized model.

2) For changes in rain frequency and rain rates, the parameterized model is limited: it fails to capture the widespread increases in extremes seen in the explicit model, with a weaker control by available water, instead only simulating larger changes where mesoscale forcings are strong. Furthermore, the range of available moisture and updrafts at times of extreme rainfall are smaller in the parameterized convection model, suggesting that it is less able to modify its environment to be conducive to higher rain rates.

3) Inadequate interaction between parameterized convection and circulations induced by land-sea temperature contrasts can limit the reliability of parameterized model's daytime response to climate change in key locations. These small-scale features are critical drivers of eastern African rainfall, especially around some of the major population centers.

The results here provide a mixed picture of how much confidence we should place in existing projections of rainfall over the region. Clearly, and as expected, the parameterized convection (representing a traditional climate model) struggles to capture the drivers and extent of extreme rainfall increases. Therefore, further convectionpermitting modeling studies over the region are needed to provide useful ensemble projections of extreme rainfall metrics. However, over Lake Victoria where nighttime mesoscale circulations drive rainfall, the two models produce qualitatively similar increases in total rainfall. Instead, the largest difference here is with past results that have suggested a decrease in mean rainfall over Lake Victoria. Our results give confidence for projections of nocturnal rainfall features from traditional climate models as long as the ensemble spans the uncertainty in drivers of mesoscale circulation such as, in this case, lake surface temperatures. The feature of larger percentage increases of rainfall on the Lake Victoria western shore in both models here, and in the previous study by Thiery et al. (2016), suggest that this may be a robust feature of climate change. Since the higher rainfall changes may be important for coastal communities, it warrents investigation in future studies. For daytime mesoscale circulations such as sea breezes, our results suggest little confidence can be placed in parameterized convection models to reliably couple the mesoscale circulations to rainfall or the response of rainfall to climate change. In locations where these mesoscale circulations are important, existing projections are likely to be less useful.

The experiments here have been designed to test the uncertainty in existing climate projections related to the representation of convection. There are some limitations 
that require careful use of the data as climate change projections: notably, the use of uniform soil properties and prescribed lake and sea surface temperatures. Because of the important effects of lakes on mesoscale circulations, as demonstrated here, it would be highly beneficial for future research to focus on the response of lake surface temperatures of Africa's Great Lakes. Accurate soil properties for the continent are also important to establish reliable highresolution projections. These two lines of research would enable better constrained simulations to further investigate the aspects of climate fundamental to the rainfall generation that is so important to people in the region.

Several conclusions have been drawn regarding extreme rainfall events. These events encompass 1 in 100 of all 3-hourly periods of rainfall. Some applications may require analysis of even more extreme events. The 10-yr length of these simulations limits the sampling of such events, and therefore any such analysis must be undertaken with care.

Another interesting result from this work is the smaller increase of easterly moisture flux in the explicit convection model compared to the parameterized convection model. This difference is associated with higher rainfall in the Lake Victoria region in the explicit model. Other studies have found the easterly moisture flux to be an important feature of climate connecting eastern equatorial Africa with the west (Giannini et al. 2018; Finney et al. 2020). By studying this feature for the first time with a convection-permitting model, we have highlighted an application of such models beyond those already presented in convection-permitting studies of the extratropics. There is scope for more detailed research of this key dynamical feature within the data used here, but understanding of equatorial African climate would also undoubtedly benefit from study of the easterly moisture flow in a range of other datasets.

The approach used here allows novel determination of uncertainty from the way in which convection is parameterized, but not from the global uncertainties, which must instead be obtained from global ensembles (Ongoma et al. 2018; Osima et al. 2018). Our results provide new detailed user-relevant information on important possible changes to eastern African climate and clearly show that parameterized models should not be the sole source of climate change information for long-lived decisions. We would anticipate our conclusions are directly relevant to other tropical regions with similar controls on weather: mountain-coastline interactions of the "Maritime Continent," the Ghats, and the Andes and regions with large tropical lake influences. Future studies should address possible changes with other models and under other emission scenarios, as well as the implications for hydrological changes, which are sensitive to extremes.
Acknowledgments. Authors Declan Finney, John Marsham, David Rowell, and Elizabeth Kendon were supported by the Natural Environment Research Council/Department for International Development (NERC/DFID, NE/M02038X/1, and NE/M019985/1) via the Future Climate for Africa (FCFA) funded project, Integrating Hydro-Climate Science into Policy Decisions for Climate-Resilient Infrastructure and Livelihoods in East Africa (HyCRISTAL). Marsham was also supported by the National Centre for Atmospheric Science via the NERC/GCRF programme ACREW: Atmospheric hazard in developing Countries: Risk assessment and Early Warning. Elizabeth Kendon gratefully acknowledges funding from the Joint U.K. BEIS/Defra Met Office Hadley Centre Climate Programme (GA01101). Authors John Marsham, Lawrence Jackson, Elizabeth Kendon, Simon Tucker and Rachel Stratton were supported by NERC/DFID via the FCFA funded project, Improving Model Processes for African Climate (IMPALA, NE/MO17176/1 and NE/M017214/1). Declan Finney thanks Philippa Chalmers for her comments on the text. The CP4A dataset generated under the FCFA IMPALA project is publicly available from the Centre for Environmental Data Analysis (CEDA) archive (https://catalogue.ceda.ac.uk/uuid/ a027093520b2432b8e782e3edefd6b47).

\section{REFERENCES}

Abel, S. J., and Coauthors, 2017: The role of precipitation in controlling the transition from stratocumulus to cumulus clouds in a Northern Hemisphere cold-air outbreak. J. Atmos. Sci., 74, 2293-2314, https://doi.org/10.1175/JAS-D-16-0362.1.

Anyah, R. O., F. H. M. Semazzi, and L. Xie, 2006: Simulated physical mechanisms associated with climate variability over Lake Victoria basin in East Africa. Mon. Wea. Rev., 134, 35883609, https://doi.org/10.1175/MWR3266.1.

Aranami, K., T. Davies, and N. Wood, 2015: A mass restoration scheme for limited-area models with semi-Lagrangian advection. Quart. J. Roy. Meteor. Soc., 141, 1795-1803, https:// doi.org/10.1002/qj.2482.

Ban, N., J. Schmidli, and C. Schär, 2015: Heavy precipitation in a changing climate: Does short-term summer precipitation increase faster? Geophys. Res. Lett., 42, 1165-1172, https://doi.org/ 10.1002/2014GL062588.

Birch, C. E., D. J. Parker, J. H. Marsham, D. Copsey, and L. Garcia-Carreras, 2014: A seamless assessment of the role of convection in the water cycle of the West African monsoon. J. Geophys. Res. Atmos., 119, 2890-2912, https://doi.org/10.1002/ 2013JD020887.

—, M. J. Roberts, L. Garcia-Carreras, D. Ackerley, M. J. Reeder, A. P. Lock, and R. Schiemann, 2015: Sea-breeze dynamics and convection initiation: The influence of convective parameterization in weather and climate model biases. J. Climate, 28, 8093-8108, https://doi.org/10.1175/JCLI-D-1400850.1 .

Collins, M., and Coauthors, 2013: Long-term climate change: Projections, commitments and irreversibility. Climate Change 
2013: The Physical Science Basis, T. F. Stocker et al., Eds. Cambridge University Press, 1029-1136.

Cook, K. H., and E. K. Vizy, 2013: Projected changes in East African rainy seasons. J. Climate, 26, 5931-5948, https://doi.org/10.1175/ JCLI-D-12-00455.1.

De Kauwe, M. G., C. M. Taylor, P. P. Harris, G. P. Weedon, and R. J. Ellis, 2013: Quantifying land surface temperature variability for two Sahelian mesoscale regions during the wet season. J. Hydrometeor., 14, 1605-1619, https://doi.org/10.1175/ JHM-D-12-0141.1.

Finney, D. L., and Coauthors, 2019: Implications of improved representation of convection for the East Africa water budget using a convection-permitting model. J. Climate, 32, 21092129, https://doi.org/10.1175/JCLI-D-18-0387.1.

_ J. H. Marsham, D. P. Walker, C. E. Birch, B. J. Woodhams, L. S. Jackson, and S. Hardy, 2020: The effect of westerlies on East African rainfall and the associated role of tropical cyclones and the Madden-Julian Oscillation. Quart. J. Roy. Meteor. Soc., https://doi.org/10.1002/qj.3698, in press.

Funk, C., and Coauthors, 2019: Examining the potential contributions of extreme "Western V" sea surface temperatures to the 2017 March-June East African drought [in "Explaining Extreme Events of 2017 from a Climate Perspective"']. Bull. Amer. Meteor. Soc., 100 (1), S55-S60, https://doi.org/10.1175/ BAMS-D-18-0108.1.

Giannini, A., B. Lyon, R. Seager, and N. Vigaud, 2018: Dynamical and thermodynamic elements of modeled climate change at the East African margin of convection. Geophys. Res. Lett., $\mathbf{4 5}$, 992-1000, https://doi.org/10.1002/2017GL075486.

Gregory, D., and P. R. Rowntree, 1990: A mass flux convection scheme with representation of cloud ensemble characteristics and stability-dependent closure. Mon. Wea. Rev., 118, 1483 1506, https://doi.org/10.1175/1520-0493(1990)118<1483: AMFCSW $>2.0 . \mathrm{CO} ; 2$.

Hoegh-Guldberg, O., and Coauthors, 2018: Impacts of $1.5^{\circ} \mathrm{C}$ global warming on natural and human systems. Global Warming of $1.5^{\circ} \mathrm{C}$, T. W. V. Masson-Delmotte et al., Eds., Cambridge University Press, 175-311, https://www.ipcc.ch/site/assets/ uploads/sites/2/2019/06/SR15_Chapter3_Low_Res.pdf.

Hohenegger, C., L. Schlemmer, and L. Silvers, 2015: Coupling of convection and circulation at various resolutions. Tellus, 67A 26678, https://doi.org/10.3402/tellusa.v67.26678.

Hook, S., R. C. Wilson, S. MacCallum, and C. Merchant, 2012: Lake surface temperature [in "State of the Climate in 2011"]. Bull. Amer. Meteor. Soc., 93 (7), S18, https://doi.org/10.1175/ 2012BAMSStateoftheClimate.1.

Huffman, G. J., and Coauthors, 2007: The TRMM Multisatellite Precipitation Analysis (TMPA): Quasi-global, multiyear, combined-sensor precipitation estimates at fine scales. J. Hydrometeor., 8, 38-55, https://doi.org/10.1175/JHM560.1.

Jackson, L. S., R. J. Keane, D. L. Finney, J. H. Marsham, D. J. Parker, C. A. Senior, and R. A. Stratton, 2019: Regional differences in the response of rainfall to convectively coupled Kelvin waves over tropical Africa. J. Climate, 32, 8143-8165, https://doi.org/10.1175/JCLI-D-19-0014.1.

Kendon, E. J., N. M. Roberts, H. J. Fowler, M. J. Roberts, S. C. Chan, and C. A. Senior, 2014: Heavier summer downpours with climate change revealed by weather forecast resolution model. Nat. Climate Change, 4, 570-576, https://doi.org/10.1038/ nclimate2258.

- R. A. Stratton, S. Tucker, J. H. Marsham, S. Berthou, D. P. Rowell, and C. A. Senior, 2019: Enhanced future changes in wet and dry extremes over Africa at convection-permitting scale. Nat. Commun., 10, 1794, https://doi.org/10.1038/s41467019-09776-9.

Kilavi, M., and Coauthors, 2018: Extreme rainfall and flooding over central Kenya including Nairobi city during the long-rains season 2018: Causes, predictability, and potential for early warning and actions. Atmosphere, 9, 472, https://doi.org/ 10.3390/atmos9120472.

MacCallum, S. N., and C. J. Merchant, 2012: Surface water temperature observations of large lakes by optimal estimation. Can. J. Remote Sens., 38, 25-45, https://doi.org/10.5589/m12-010.

Mahoney, K., M. Alexander, J. D. Scott, and J. Barsugli, 2013: High-resolution downscaled simulations of warm-season extreme precipitation events in the Colorado front range under past and future climates. J. Climate, 26, 8671-8689, https:// doi.org/10.1175/JCLI-D-12-00744.1.

Marsham, J. H., N. S. Dixon, L. Garcia-Carreras, G. M. S. Lister, D. J. Parker, P. Knippertz, and C. E. Birch, 2013: The role of moist convection in the West African monsoon system: Insights from continental-scale convection-permitting simulations. Geophys. Res. Lett., 40, 1843-1849, https://doi.org/10.1002/grl.50347.

O'Gorman, P. A., and C. J. Muller, 2010: How closely do changes in surface and column water vapor follow Clausius-Clapeyron scaling in climate change simulations? Environ. Res. Lett., 5, 025207, https://doi.org/10.1088/1748-9326/5/2/025207.

Ongoma, V., H. Chen, and C. Gao, 2018: Projected changes in mean rainfall and temperature over East Africa based on CMIP5 models. Int. J. Climatol., 38, 1375-1392, https://doi.org/ $10.1002 /$ joc. 5252 .

O'Reilly, C. M., and Coauthors, 2015: Rapid and highly variable warming of lake surface waters around the globe. Geophys. Res. Lett., 42, 10 773-10 781, https://doi.org/10.1002/2015GL066235.

Osima, S., and Coauthors, 2018: Projected climate over the Greater Horn of Africa under $1.5^{\circ} \mathrm{C}$ and $2^{\circ} \mathrm{C}$ global warming. Environ. Res. Lett., 13, 065004, https://doi.org/10.1088/1748-9326/aaba1b.

Otieno, V. O., and R. O. Anyah, 2013: CMIP5 simulated climate conditions of the Greater Horn of Africa (GHA). Part II: Projected climate. Climate Dyn., 41, 2099-2113, https://doi.org/ 10.1007/s00382-013-1694-z.

Prein, A. F., and Coauthors, 2015: A review on regional convectionpermitting climate modeling: Demonstrations, prospects, and challenges. Rev. Geophys., 53, 323-361, https://doi.org/10.1002/ 2014RG000475.

, C. Liu, K. Ikeda, S. B. Trier, R. M. Rasmussen, G. J. Holland, and M. P. Clark, 2017: Increased rainfall volume from future convective storms in the US. Nat. Climate Change, 7, 880-884, https://doi.org/10.1038/s41558-017-0007-7.

Reynolds, R. W., T. M. Smith, C. Liu, D. B. Chelton, K. S. Casey, and M. G. Schlax, 2007: Daily high-resolution-blended analyses for sea surface temperature. J. Climate, 20, 5473-5496, https://doi.org/10.1175/2007JCLI1824.1.

Rowell, D. P., B. B. B. Booth, S. E. Nicholson, and P. Good, 2015: Reconciling past and future rainfall trends over East Africa. J. Climate, 28, 9768-9788, https://doi.org/10.1175/JCLI-D-150140.1.

, C. A. Senior, M. Vellinga, and R. J. Graham, 2016: Can climate projection uncertainty be constrained over Africa using metrics of contemporary performance? Climatic Change, 134, 621-633, https://doi.org/10.1007/s10584-015-1554-4.

Shongwe, M. E., G. J. van Oldenborgh, B. van den Hurk, and M. van Aalst, 2011: Projected changes in mean and extreme precipitation in Africa under global warming. Part II: East Africa. J. Climate, 24, 3718-3733, https://doi.org/10.1175/ 2010JCLI2883.1. 
Smith, R. N., 1990: A scheme for predicting layer clouds and their water content in a general circulation model. Quart. J. Roy. Meteor. Soc., 116, 435-460, https://doi.org/10.1002/ qj. 49711649210.

Stratton, R. A., and Coauthors, 2018: A pan-African convectionpermitting regional climate simulation with the Met Office Unified Model: CP4-Africa. J. Climate, 31, 3485-3508, https:// doi.org/10.1175/JCLI-D-17-0503.1.

Taylor, C. M., and Coauthors, 2017: Frequency of extreme Sahelian storms tripled since 1982 in satellite observations. Nature, 544, 475-478, https://doi.org/10.1038/nature22069.

Thiery, W., H.-J. Panitz, E. Davin, and N. V. Lipzig, 2015: The impact of the African Great Lakes on the regional climate. J. Climate, 28, 4061-4085, https://doi.org/10.1175/JCLI-D-14-00565.1.

— E. L. Davin, S. I. Seneviratne, K. Bedka, S. Lhermitte, and N. P. M. van Lipzig, 2016: Hazardous thunderstorm intensification over Lake Victoria. Nat. Commun., 7, 12786, https://doi.org/ 10.1038/ncomms12786.

Vanderkelen, I., N. P. M. van Lipzig, and W. Thiery, 2018: Modelling the water balance of Lake Victoria (East Africa)-Part 2: Future projections. Hydrol. Earth Syst. Sci., 22, 5527-5549, https://doi.org/10.5194/HESS-22-5527-2018.

van Vuuren, D. P., and Coauthors, 2011: The representative concentration pathways: An overview. Climatic Change, 109, 5, https://doi.org/10.1007/s10584-011-0148-z.

Walters, D., and Coauthors, 2017: The Met Office Unified Model global atmosphere 6.0/6.1 and JULES global land 6.0/6.1 configurations. Geosci. Model Dev., 10, 1487-1520, https:// doi.org/10.5194/gmd-10-1487-2017.

— , and Coauthors, 2019: The Met Office Unified Model global atmosphere 7.0/7.1 and JULES global land 7.0 configurations. Geosci. Model Dev., 12, 1909-1963, https://doi.org/10.5194/ GMD-12-1909-2019.

Willetts, P. D., J. H. Marsham, C. E. Birch, D. J. Parker, S. Webster, and J. Petch, 2017: Moist convection and its upscale effects in simulations of the Indian monsoon with explicit and parametrized convection. Quart. J. Roy. Meteor. Soc., 143, 1073-1085, https://doi.org/10.1002/qj.2991.

Williams, K., J. Chamberlain, C. Buontempo, and C. Bain, 2015: Regional climate model performance in the Lake Victoria Basin. Climate Dyn., 44, 1699-1713, https://doi.org/10.1007/ s00382-014-2201-x.

Wilson, D. R., A. C. Bushell, A. M. Kerr-Munslow, J. D. Price, and C. J. Morcrette, 2008: PC2: A prognostic cloud fraction and condensation scheme. I: Scheme description. Quart. J. Roy. Meteor. Soc., 134, 2093-2107, https://doi.org/10.1002/qj.333.

Wood, N., and Coauthors, 2014: An inherently mass-conserving semi-implicit semi-Lagrangian discretization of the deepatmosphere global non-hydrostatic equations. Quart. J. Roy. Meteor. Soc., 140, 1505-1520, https://doi.org/10.1002/qj.2235.

Xie, P., R. Joyce, S. Wu, S.-H. Yoo, Y. Yarosh, F. Sun, and R. Lin, 2017: Reprocessed, bias-corrected CMORPH global highresolution precipitation estimates from 1998. J. Hydrometeor., 18, 1617-1641, https://doi.org/10.1175/JHM-D-16-0168.1. 